MLM-MU - $-90-69-0003$

DE91 001320

\title{
Kapton HN Investigations
}

M. K. Williams, A. E. Smith (SNLA), M. A. Huelskamp, K. P. Armstrong, J. L. Brandon, and J. M. Lavoie

Issued: September 28, 1990

\section{MOUND}

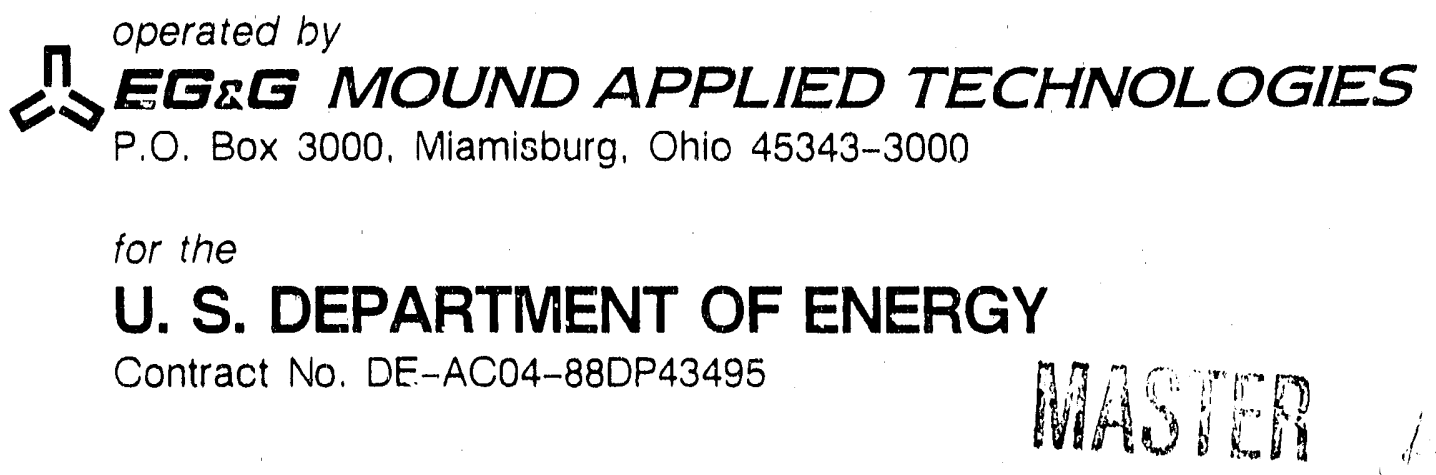




\section{Contents}

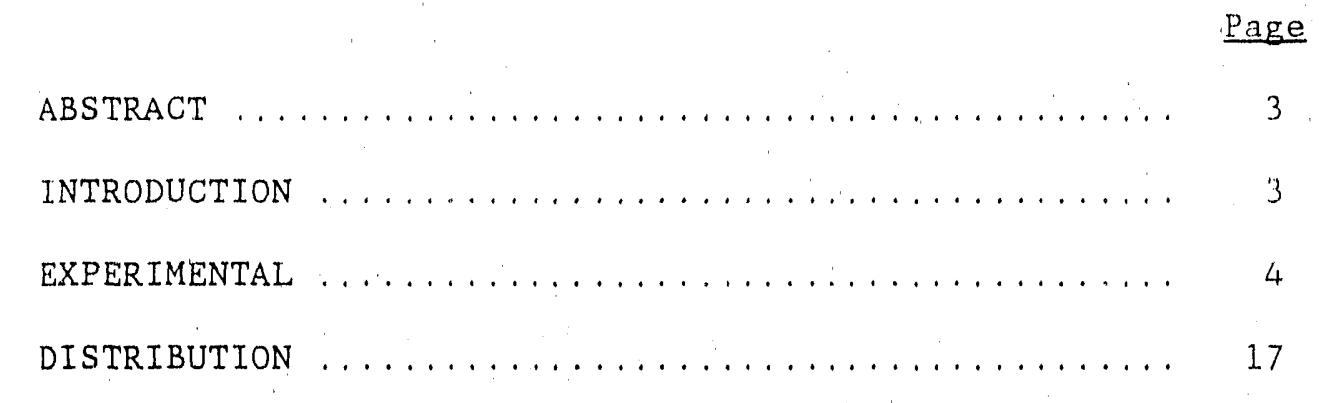




\section{Abstract}

Kapton HN properties and the properties of the slip additive calcium phosphate dibasic $\left(\mathrm{CaHPO}_{4}\right)$ were investigated.

Impurity analyses were performed on the compound by inductively coupled plasma (ICP) and ion chromatography (IC). Other analyses on the slip additive included: processing solution dissolution analysis, high-explosive compatibility studies, scanning electron microscopy/energy dispersive spectroscopy (SEM/EDS), and particle size distribution. Testing and analysts were also performed on Kapton $\mathrm{HN}$ film and other polyimide films that could serve as possible replacements for Kapton HN. The polyimide films that were tested are: Upilex-R, Upilex-S, Upilex-SGA, and Apical. The analyses performed were: infrared (IR), x-ray photoelectron spectroscopy (XPS), SEM/EDS, high-potential breakdown testing, (PVD) physical vapor deposition adhesion tests, and peel tests. Upilex-s flyer cables were also fabricated and successfully test fired.

In addition to these raw material tests, production cables were chemically treated and destructively (high potential) tested. A long-term aging environment for production cables was also selected, and aging tests were begun.

\section{Introduction}

Early in the 1980s, DuPont introduced a "new" Kapton that was designated Kapton HN. Kapton $H$ was already being used extensively in Mound's flexible cables, and soon after its introduction, we began receiving the new Kapton HN. By 1987, Kapton $\mathrm{H}$ was only being made by DuPont as a special order item.

Kapton HN is Kapton $H$, but with a slip additive added. Analyses at Mound showed that the additive was calcium phosphate dibasic $\left(\mathrm{CaHPO}_{4}\right)$. SEM (Scanning electron microscopy) has shown that some of the slip additive particles are large ( $\approx 80 \%$ of the thickness of the polyimide film), some protrude from the surface of the film, and some are cracked.* Work at SNLA

*Acton, A. E., "Kapton H versus Kapton HN Film for Flexible Circuits," a report to W. B. Vandermolen, 30 September 1987. 
and Mound has shown that chemical processing with $10 \% \mathrm{KOH}$ can dissolve the Kapton polyimide and cause some of these particles to fall out of the film leaving pits in the surface. These observations caused concern over the electrical and mechanical integrity of the film and the long-term reliability of products made with Kapton HN.

\section{Experimental}

This section is divided into three subsections. First, work performed on the slip additive in Kapton $H N$ is presented, then work performed nn polyimide films, and, last, work with fully fabricated components.

\section{Slip Additive}

As mentioned in the Introduction, the slip additive in Kapton $H N$ is calcium phosphate dibasic $\left(\mathrm{CaHPO}_{4}\right)$. The identity of this compound was determined by P. S. Wang and others at Mound early in 1987. Calcium phosphate dibasic is soluble in acids, slightly soluble in water, and somewhat less soluble in more basic solutions. SEN of the powder (Figure 1) shows that it

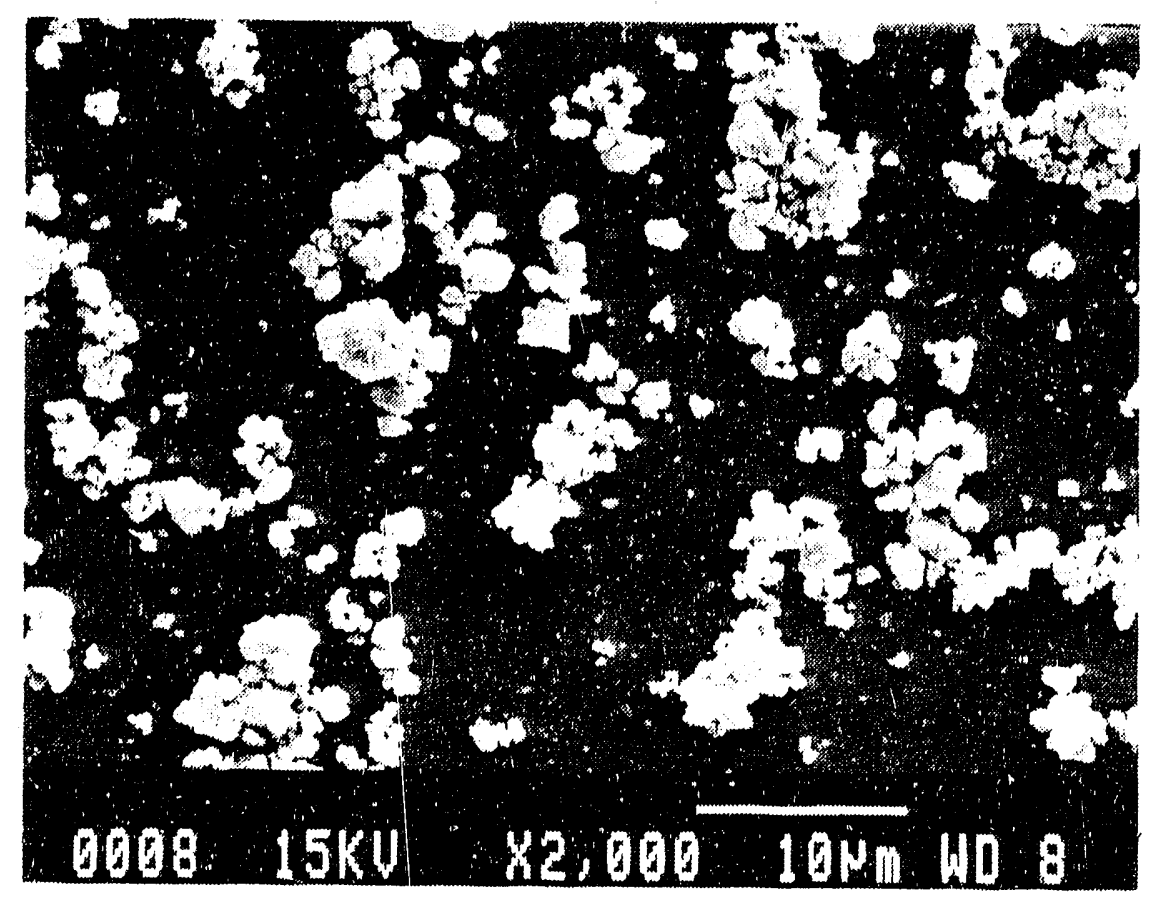

Figure 1 - Scanning electron micrograph of $\mathrm{CaHPO}_{4}$ showing the powder's tendency to form agglomerates. 
forms agglonerates from smaller particles. First attempts at preparing SEA samples were unsuccessful because of the tendency of the slip additive to agglomerate. The SEM sample shown in Figure 1 was made by ultrasonically treating a small amount of the additive in ethanol, then wicking some of that mixture into an eyedropper and spraying it onto the substrate. EDS (energy dispersive spectroscopy) of the additive showed no major impurities.

The slip additive was also analyzed for impurities bv ICP (inductively coupled plasma) and IC (ion chromatography). These results and the vendor specifications are shown in Table 1. No major impurities were found, but the IC detection limit for fluoride is $400 \mathrm{ppm}$ and the vendor would accept as much as $2500 \mathrm{ppm}$ choride. This sample, however was much lower in choride.

Manufacture of flexible cables at Mound involves passing the cable through various solutions to clean, etch, develop, and plate circuits. The extent of solubility of calcium phosphate dibasic $\left(\mathrm{CaHPO}_{4}\right)$ in these solutions was determined by detecting the concentration of calcium by ICP; Table 2 shows

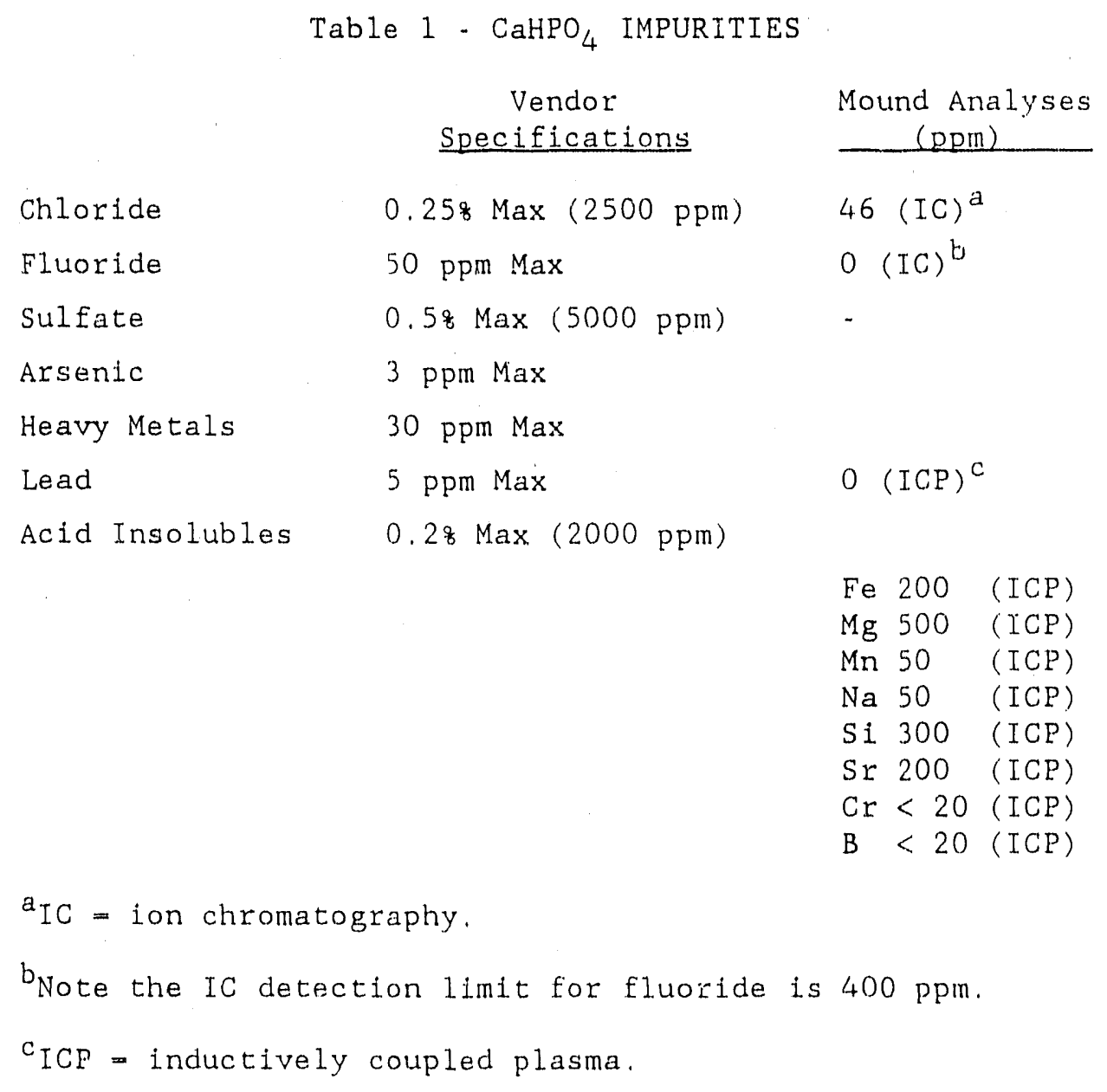




\section{Tab1e 2 - MOUND PROCESSING SOLUTIONS WERE CONTAC'TED WITH CaHPO 4 TO DETERMINE SOLUBILITY}

\begin{tabular}{|c|c|c|}
\hline & $\begin{array}{l}\text { Ca Before } \\
\text { S } \mu g / m L)\end{array}$ & $\begin{array}{l}\text { Ca After } \\
(\mu \mathrm{g} / \mathrm{mL})\end{array}$ \\
\hline Reverse Osmosis Water & () & 53 \\
\hline Stripper $58 \mathrm{kOH}$ & 0 & $<2$ \\
\hline Developer $\mathrm{Na}_{2} \mathrm{CO}_{3}$ & 0 & 10 \\
\hline Plating $158 \mathrm{H}_{2} \mathrm{SO}_{4}$ & 0 & 875 \\
\hline Diff. Bond $50 \% \mathrm{HCl}$ & 0 & 27,787 \\
\hline 200 Proof $\mathrm{C}_{2} \mathrm{H}_{5} \mathrm{OH}$ & 0 & $<2$ \\
\hline Etchant $\mathrm{FeCl}_{3}$ & 58 & 26,401 \\
\hline Plating $\mathrm{Ni}\left(\mathrm{SO}_{3} \mathrm{NH}_{2}\right)_{2}$ & 0 & 584 \\
\hline
\end{tabular}

the results. In general, the more acidic the solution the more slip additive it could dissolve. The concentration $(\mu \mathrm{g} / \mathrm{mL})$ of $\mathrm{CaHPO}_{4}$ can be back calculated by dividing the $\mu \mathrm{g} / \mathrm{mL}$ of Ca by 0.29 . Also, this test was performed by putting $10 \mathrm{~g}$ of $\mathrm{slip}$ additive in $100 \mathrm{~mL}$ of each solution; so if all the slip additive were dissolved, the maximum concentration would be $0.1 \mathrm{~g} / \mathrm{mL}$ of $\mathrm{CaHPO}_{4}$.

Since most Kapton film used in cables at Mound is thin (either 1 or $2 \mathrm{mils}$ ), the particle size distribution of the $\mathrm{CaHPO}_{4}$ is important. DuPont claims no particles larger than $7 \mu \mathrm{m}$ diameter go into their films, but one $40 \mu \mathrm{m}$ particle was observed in a $2 \mathrm{mil}(50 \mu \mathrm{m})$ film.* The particle size distribution was determined by using a Coulter Counter. The distribution is shown graphically in Figure 2. Most of the particles are from 1 to $5 \mu \mathrm{m}$ in diameter. However, 48 of the particles are 10 to $20 \mu \mathrm{m}$ in diameter, and none larger than $20 \mu \mathrm{m}$ were found in this sample.

In some applications, Kapton $H N$ is in direct contact with high explosives in detonators. Because of this contact and because the slip additive is exposed at the surface of the film, high-explosive compatibility tests were perfurmed with $\mathrm{CaHPO}_{4}$. The explosives tested were HNS (hexanitrostilbene), TATB (triaminotrinitrobenzene), HMX (cyclotetramethylene tetranitramine), and

*Acton, A. E., "Kapton H versus Kapton HN Film for Flexible Circuits," a report to W. B. Vandermolen, 30 September 1987. 


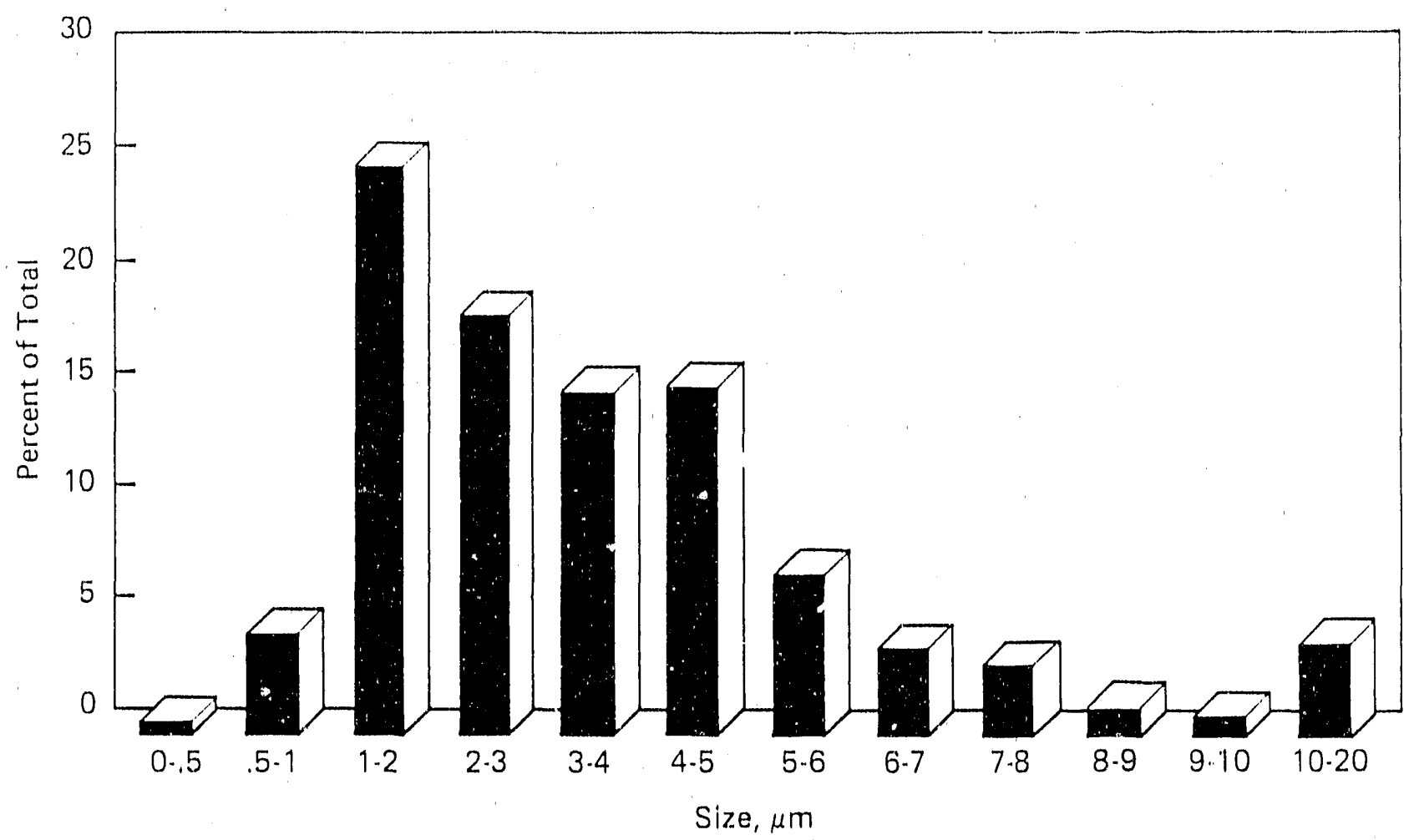

Figure 2 - The particle size distribution of $\mathrm{CaHPO}_{4}$ as determined by Coulter Counter analysis.

LX-16 [PETN (pentaerythritol tetranitrate) with a binder]. HNS, TATB, and HMX were compatible with the $\mathrm{CaHPO}_{4}$. LX-16 showed some reactivity with $\mathrm{CaHPO}_{4}$ at 120 and $100^{\circ} \mathrm{C}$. This test was performed using a $50 / 50$ mixture of the slip additive and the high explosive. Since a mixture of this nature is very unlikely to ever occur in a component, a test using actual Kapton $H N$ and LX-16 was conducted. The results of that test showed that LX.16 is compatible with Kapton HN.

\section{Testing of Polyimide Films}

This subsection covers the testing of the following polyimide films: Kapton HN, Kapton H, Apical, Upilex-S, Upilex-R, Upilex-SGA.

Infrared (IR) spectra, which were determined for Upilex-S, Kapton H, Aplcal, Upilex-R, and Upilex-SGA (Figures 3-7), showed that Upilex-S and Upilex-SGA have essentially identical structures. Apical and Kapton $H$ also showed only minor structural differences, whereas structural differences between Upilex-S/Upilex-SGA and Apical/Kapton $H$ were very evident. Upilex-R was 


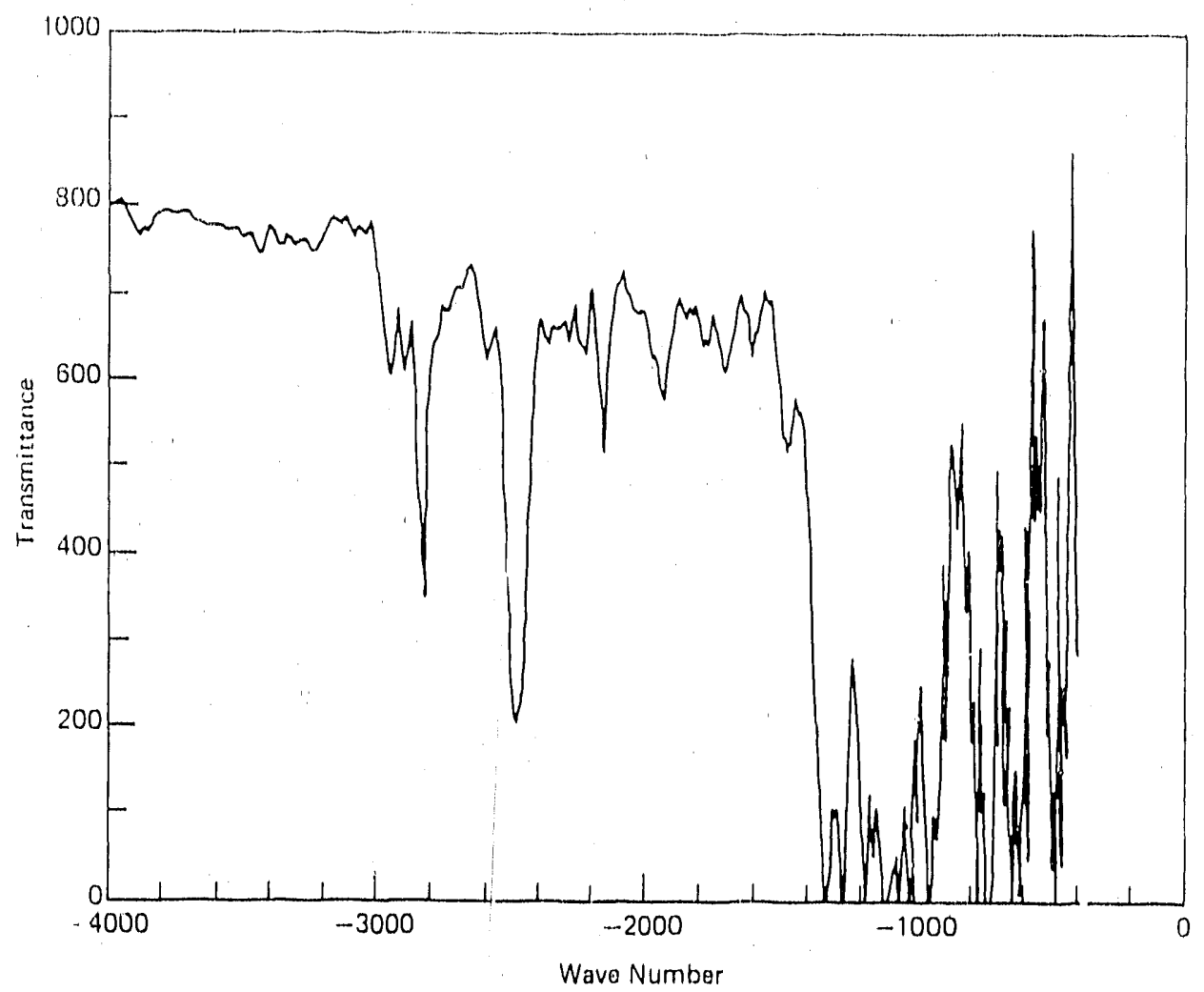

Figure 3 - IR spectral determination for Upilex-S.

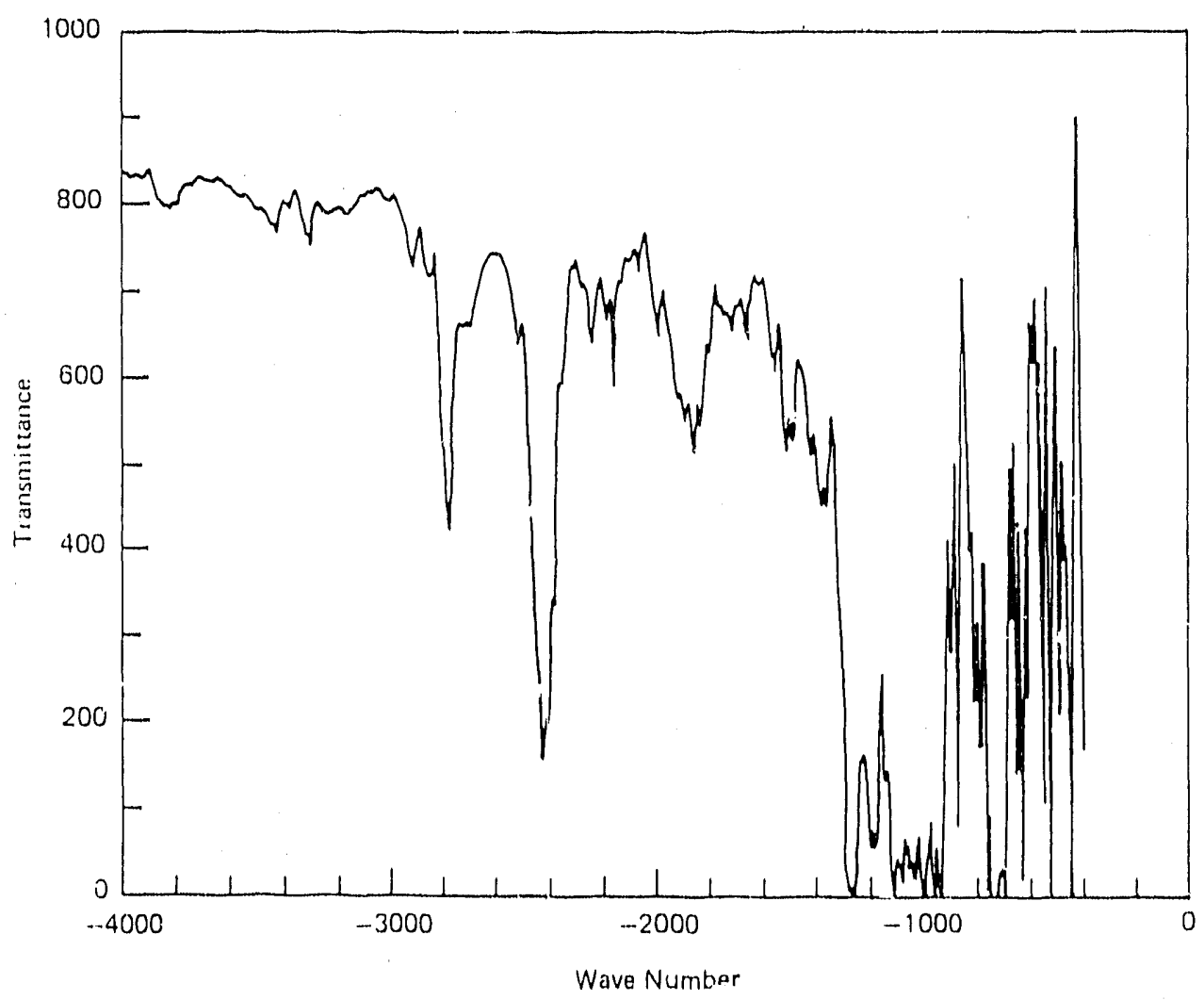

Figure 4 - IR spectral determination for Kapton $H$. 


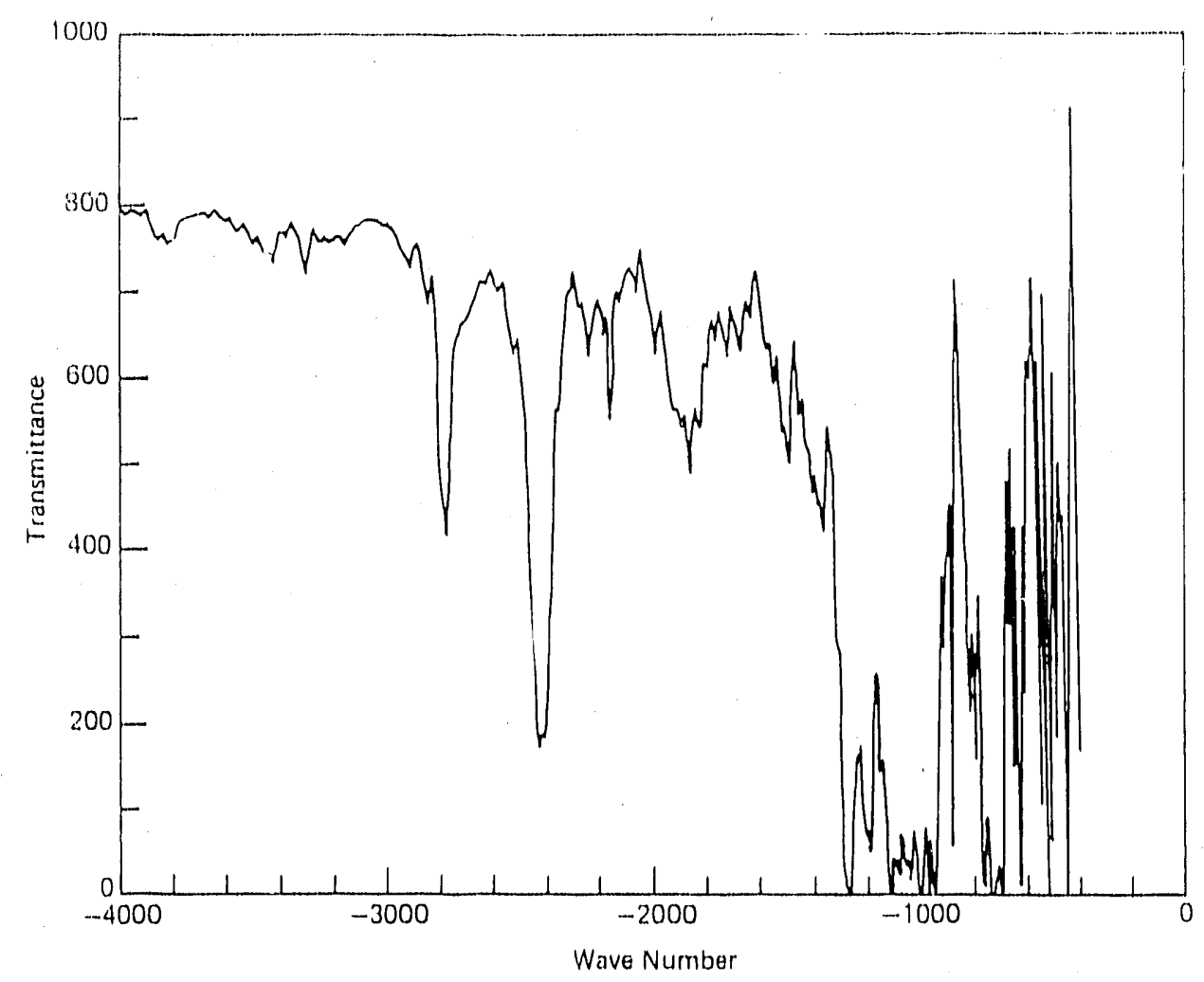

Figure 5 - IR spectral determination for Aplcal.

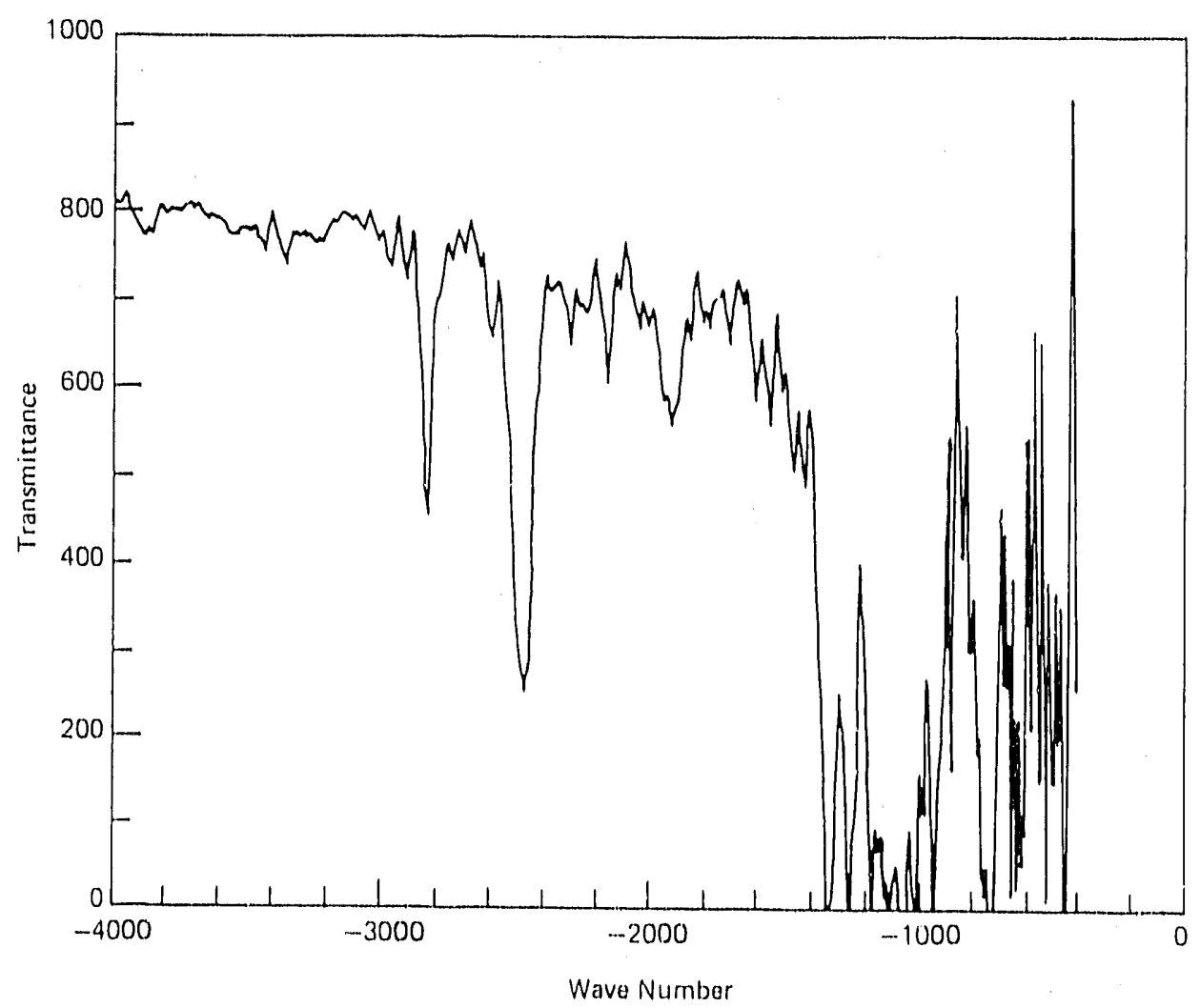

Figure 6 - IR spectral detemination for Upilex-R. 


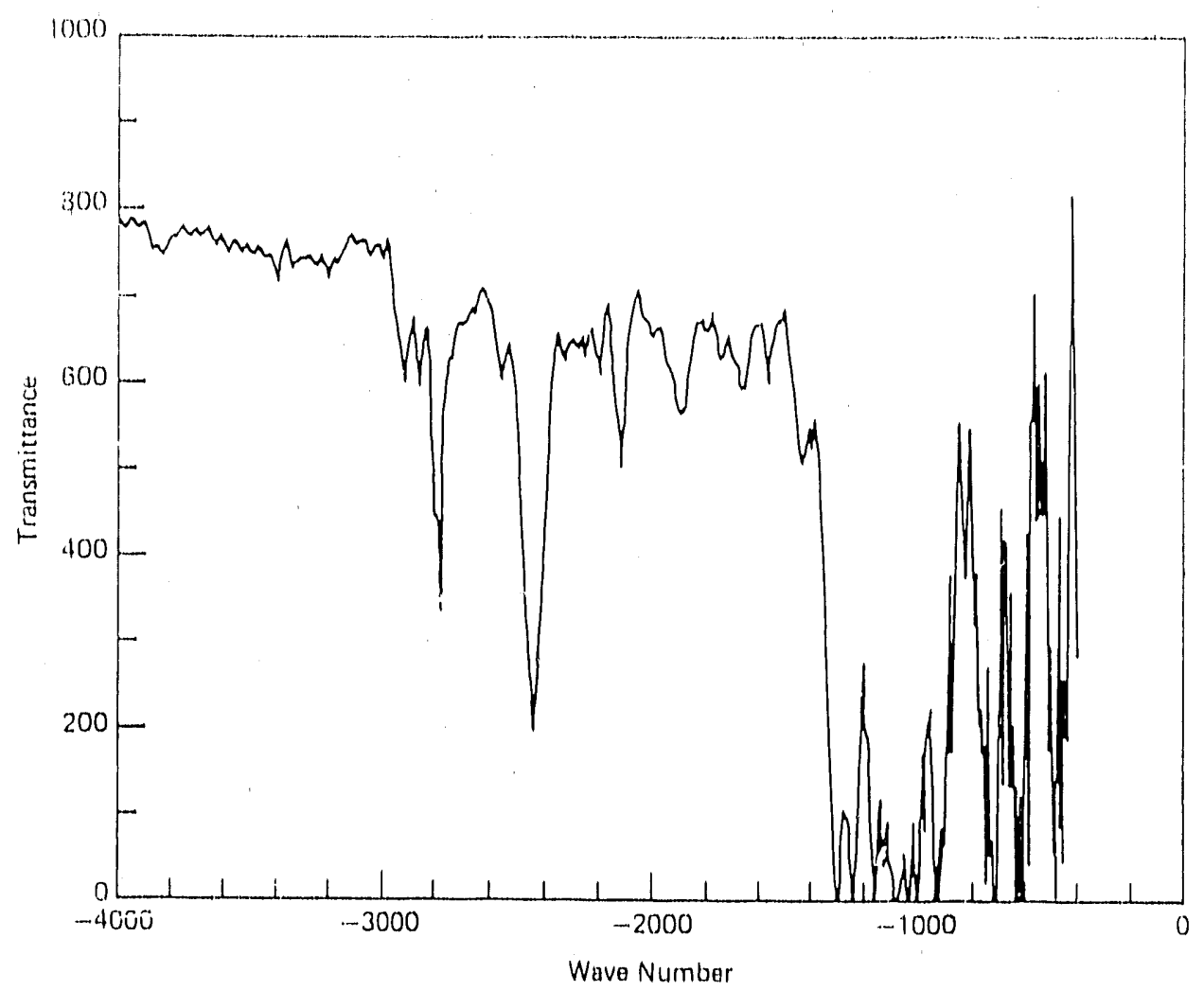

Flgure 7 - IR spectral determination for Upilex-SGA.

different from all the other polylmides, showing some simliartties to both Upilex-S and Kapton H. IR spectra were not determined for Kapton HN since the main difference between Kapton $H$ and Kapton $H N$ is the prescence of $\mathrm{CaHPO}_{4}$ (the slip additive) in Kapton HN. XPS ( $x$ - ray photoelectron spec. troscopy) determinations were made on the same polylmides to determine if one side of the Upilex-SGA was coated with something to enhance bordability. No coating on Uptlex-SGA was positively detected. The differences from instde to outside of the Upllex-SGA film, with or without cleaning, were no greater than other films that were known to be uncoated. Silicon, however, was detected on the Upllex-SGA. The silicon wes present on both sides of the film and could be partially removed with acetone. Sllicon was also detected on Upilex-S/Upilex-SGA by SEM/EDS and is beliteved to be a surface contami." nant, posstbly from a release agent, The percentages of carbon, oxygen, nitrogen, and silicon, detected by XPS, are given lin Table 3 .

The Katon and Upilex films were tested for high-voltage breakclown using 1. - in. diameter brass contacts in Fluorotnert.* These tests were conducted to *A series of perfluorinated Liquids used for cleaning electronic components after testing. 


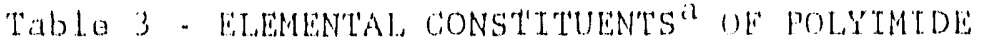
WHAS AS DETERMINED Bi RPS

\begin{tabular}{|c|c|c|c|c|c|c|}
\hline & & & & & & \\
\hline & Samp le & $\mathrm{C}=\mathrm{O}$ & $\mathrm{C}-\mathrm{H}$ & 0 & $N$ & $\mathrm{SL}$ \\
\hline Kapton $\mathrm{H}$ & outside & 7.8 & 76.7 & 13.4 & 2.4 & $\cdots$ \\
\hline & Iristede & 10.5 & 70.0 & 1.5 .2 & 4.4 & $\cdots$ \\
\hline & outstde, acetone wipe & 1.2 .3 & 62.2 & $1.8,8$ & 6.6 & $\ldots$ \\
\hline & Instcle, acotone wipe & 11.9 & 62.6 & 19.0 & 6.5 & $\cdots$ \\
\hline Up11ex-R & outside & 9.8 & 72.5 & 13,9 & 3.9 & $\cdots$ \\
\hline & Instde & 9.9 & 69.0 & 15.6 & $5, i$ & $\cdots$ \\
\hline & outside, acetone wipe & 1.1 .2 & 67.4 & 15.8 & 5.5 & $\ldots$ \\
\hline & Instcle, acetone wipe & 11.2 & 67.2 & 16.0 & 5.6 & $\cdots-$ \\
\hline Up11ex - SGA & outside & 11.7 & 64.0 & 17.9 & 4,9 & 1.5 \\
\hline & Inside & 11.4 & 59.6 & 20,7 & 6.1 & 2.1 \\
\hline & outside, acetone wipe & 12.1 & 61.8 & 18.7 & 6.4 & 0.96 \\
\hline & Instde, acetone wipe & 13.4 & 62.1 & 17.1 & 6.7 & 0.73 \\
\hline Upj.1ex-S & outside & 13.6 & 64.0 & 16.3 & 5.8 & $<0,4$ \\
\hline & Inside & 13.3 & 65.1 & 1.4 .7 & 6.9 & $\ldots$ \\
\hline & outside, acetone wipe & 12.4 & 64.4 & 15.7 & $\therefore 1$ & $<0.3$ \\
\hline & Irride, acetone wipe & 12.1 & 65.1 & 15.4 & 7.5 & $\cdots$ \\
\hline Aplcal & outside & 11.6 & 63.4 & 19.0 & 6.0 & $\cdots$ \\
\hline & Inside & 13.8 & 58.6 & 20.9 & 6.6 & $\cdots$ \\
\hline & outside, acetone wipe & 12.1 & 61.7 & 19,3 & 6.9 & $\cdots$ \\
\hline & inside, acetone wipe & 12.2 & 61.5 & 19.1 & 7.2 & $\cdots$ \\
\hline
\end{tabular}

a By percent.

determine the ablifty of the fllm to act as an insulator, one of tes primary functions In Mound flexible cables. As shown below, Kapton H, Kapton HN, and Upllex-R had average breakdown voltage values $\ln$ the $20-22 \mathrm{kV}$ range, whereas Upllex-S and Upilex-SGA had average breakdown voltage values in the $16-17 \mathrm{kV}$ range.

$\begin{array}{ll}\text { Kapton } \mathrm{H} & =21.51 \pm 2.02 \mathrm{kV} \\ \text { Kapton HN } & =20.61 \pm 7.67 \mathrm{kV} \\ \text { Up1.1ex-R } & =21.42 \pm 0.16 \mathrm{kV} \\ \text { Up1.1ex-S } & =16.48 \pm 1.07 \mathrm{kV} \\ \text { Up1lex-SGA } & =16.44 \pm 0.87 \mathrm{kV}\end{array}$

The confidence limits on the mean values were calculated at the 958 confi. dence limit using the formula: mean $\pm \mathrm{ts} / \mathrm{J}$, where $t$ is the student $5, \mathrm{~s}$ is the standard deviation, and $n$ is the number of samples. The actual values that were obtalned are given in Table 4. 


\begin{tabular}{|c|c|c|c|c|}
\hline Kapton HN & Kapton H & Upt1ex-R & $\underline{\text { UpLLex }}=\underline{S}$ & Upt Lex-SCA \\
\hline 21.21 & 19.84 & 21.73 & $1 \% .90$ & 1.6 .57 \\
\hline 22.43 & 24.01 & 21.47 & 1.7 .05 & 15.54 \\
\hline \multirow[t]{5}{*}{20.89} & 17.98 & 21.38 & 16.18 & 17.70 \\
\hline & & 21.44 & 16.19 & 1.4 .93 \\
\hline & & 21.45 & 15.36 & 16.66 \\
\hline & & 21.14 & 17.79 & 17,19 \\
\hline & & 21.34 & 14.89 & 16.49 \\
\hline
\end{tabular}

For the bridges in Mound cables, the adhestion of a thin metal coating to the f1lm is very important. To compare the adhesion strengths of a thin metal. film to each of these polyimides, actual bridges are made by PVD (physical vapor deposition). A plasma cleaning step is used at the beginning of the metal deposition process. Half of each bridge has a stud glued to the metal. coat, and a ceramic disk (aligned with the stud above) glued to the underside of the film (Flgure 8). The assembly is then pulled apart in a test machine, and the force is measured; the fallure mode is also noced. Some parts fiall moro thar one way, but the first fallure is the significant one. Table 5 shows the average strength at fallure, the confidence limits, and the fallure mode. In referring to Table 5 and Figure 8, the substrata is the polyimide film, ADH Indicates a fallure in the epoxy adhestve between the stud and the bridge, As indicates a fallure in achesion of the metal to the polyimide, Is indicates a fallure in the polyimide stubstrate, and SW Indicates a fallure of: the scotchweld adhestve. From Table 5, it can be clearly seen that the Upilex polyimides had the greater adhesion strengths with the metal film; this could be related to their greater modulus values.

The fact that Kapton HN had more fallures in the substrate than any other fllm was also noteworthy. 


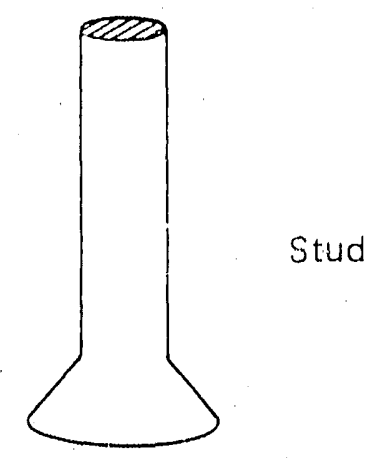

$\mathrm{ADH}$ Epoxy $\mathrm{Cr} / \mathrm{Cu}$

AS

is

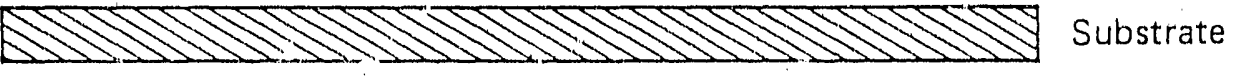

SW

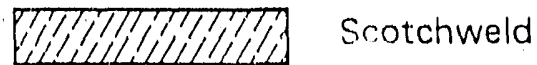

VIIIIIIIIIIID Ceramic

Figure 8 - Exploded view of half a bridge showing: stud glued to metal coat, and ceramic disk (aligned with the stud above) glued to the underside of the substrate (polyimide film). The potential failure modes (ADH, $A S, I S$, and $S W$ ) are also shown.

Table 5 - PVD BUTT TENSILE TEST RESULTS

Rupture Strength

at Failure (psi)

Material

$\bar{x} \pm \operatorname{ts} / \ln 9$ df

First Failure Mode
$\underline{\text { ADH }} \underline{\text { AS }}$ IS $\underline{\text { SW }} \underline{\text { NE }}$

Kapton $\mathrm{H}$

$5.43 \pm 0.89$

Kapton HN

$5.77 \pm 0.32$

Upilex-S

$8.67 \pm 0.55$

Upilex-R

$7.53 \pm 0.86$

$\begin{array}{rllll}4 & 3 & 1 & 2 & 0 \\ 3 & 0 & 5 & 2 & 0 \\ 5 & 3 & 0 & 1 & 1 \\ 10 & 0 & 0 & 0 & 0 \\ 10 & 0 & 0 & 0 & 0 \\ 9 & 0 & 0 & 1 & 0\end{array}$

$8.76 \pm 0.74$

Upilex-SGA

$5.75 \pm 0.40$

Apical 
Peel tests were performed on all of the rolyinide films under study. The results are tabulated in Table 6. All of the results were much lower than expected. Past peel tes ss with Kapton $H$ and Kapton HN averaged around 7 lb/ linear in. Since all the samples yielded lower than expected results, this work will be repeated.

Besides being used as an insulating medium, polyimide films (Kapton) are used as flyer material in Mound's flexible cables. Flyer performance of Upilex-S was compared to that of Kapton $H$ by fabricating MAD-1.079 cables with Upilex.S flyers. The data summarized in Figure 9 indicate that there is little if any difference between the performance of a Kapton flyer and an Upilex-S flyer.

\section{Testing of Fully Fabricated Components}

Some of the cable manufacturing steps involve the use of an etching solution that contains potassium hydroxide $(\mathrm{KOH})$. Since this step, which has been known to dissolve Kapton, causes some of the slip additive ( $\mathrm{CaHPO}_{4}$ ) particles to be released from the surface of the film, concern was expressed about the electrical integrity of the film with pits in its surface. Consequently, Eive MC3926 cables were exposed to a 1.08 solution of $\mathrm{KOH}$ at $150^{\circ} \mathrm{F}$ for $2 \mathrm{~min}$. This exposure represents a slightly more intrusive environment than what would be experienced during the course of normal processing. Afterwards, these cables, along with five untreated cables, were high-potential breakdown tested to destruction. The results, which are tabulated in Table 7, show

Table 6 - PEEL STRENGTH TEST RESULTS ${ }^{a}$

\begin{tabular}{|c|c|c|c|c|c|c|c|c|}
\hline Sample No. & 1 & 2 & 3 & 4 & 5 & 6 & 7 & 8 \\
\hline Apical & $T^{b}$ & $\mathrm{~T}$ & 2.0 & $\mathrm{~T}$ & $\mathrm{~T}$ & $\mathrm{~T}$ & 1.5 & $\mathrm{~T}$ \\
\hline Upilex-R & 1.1 & 1.1 & 1.3 & 1.4 & 1.5 & 1.3 & 0.97 & 1.1 \\
\hline Upilex-SGA & 3.5 & 3.7 & 2.9 & 4.1 & 3.6 & 3.2 & 3.0 & 3.1 \\
\hline Upilex-S & 3.2 & 4.2 & $\mathrm{~T}$ & 4.7 & 2.7 & 2.8 & 4.3 & 4.2 \\
\hline Kapton $\mathrm{H}$ & $\mathrm{T}$ & $\mathrm{T}$ & $\mathrm{T}$ & $T$ & $\mathrm{~T}$ & $\mathrm{~T}$ & 3.4 & $\mathrm{~T}$ \\
\hline Kapton HN & 3.6 & 2.9 & 3.3 & 2.6 & 2.7 & 3.0 & 2.6 & 2.7 \\
\hline
\end{tabular}




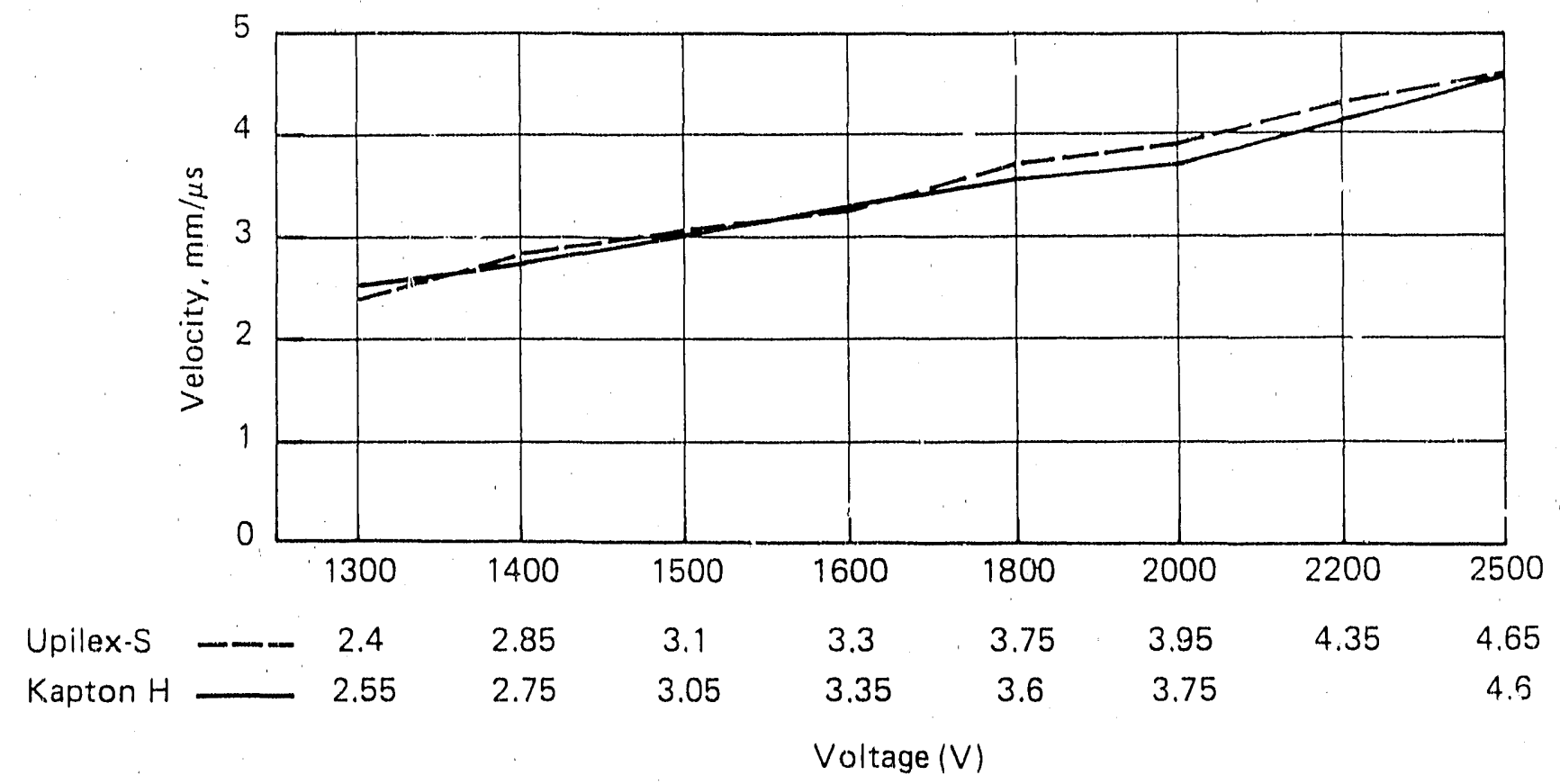

Figure 9 - VISAR results show that there is little difference in performance between Upilex-S and Kapton $H$ flyers.

Table 7 - HIGH POTENTIAL BREARDOWN TEST RESULTS

\begin{tabular}{|c|c|c|}
\hline & Serial No. & $\begin{array}{l}\text { Vol tage } \\
\text { (kv) }\end{array}$ \\
\hline \multirow[t]{5}{*}{ Untreated } & 8006 & 36 \\
\hline & 8306 & 27 \\
\hline & 8326 & 36 \\
\hline & 8856 & 36 \\
\hline & 8992 & 38 \\
\hline \multirow[t]{5}{*}{ Treated ${ }^{a}$} & 8637 & 38 \\
\hline & 8656 & 36 \\
\hline & 8689 & 32 \\
\hline & 8753 & 39 \\
\hline & 8904 & 39 \\
\hline
\end{tabular}

a Five MC3926 cables were treated with $\mathrm{KOH}$ at $150^{\circ} \mathrm{F}$ for $2 \mathrm{~min}$, followed by a $50 \% \mathrm{HCl}$ rinse at $78^{\circ} \mathrm{F}$ before being high potential tested to destruction. 
that all of the cables retalned excellent insulating properties. The lowest failure was at $27 \mathrm{kV}$ and that was one of the untreated cables.

The finai concern is long-term aging, and an aging envirotment has been selected. The cables will be stored at 528 relative humidity (RH) and ambient temperature for $24 \mathrm{hr}$ and then $928 \mathrm{RH}$ and $40^{\circ} \mathrm{C}$ for $24 \mathrm{hr}$. This cycle will be repeated until the cable has been appropriately aged; then, the cable will be visually inspected for such deleterious effects as delamination and discoloration before being high-potential breakdown tested to destruction. These results will then be compared to aged cables that have seen no special environment. 

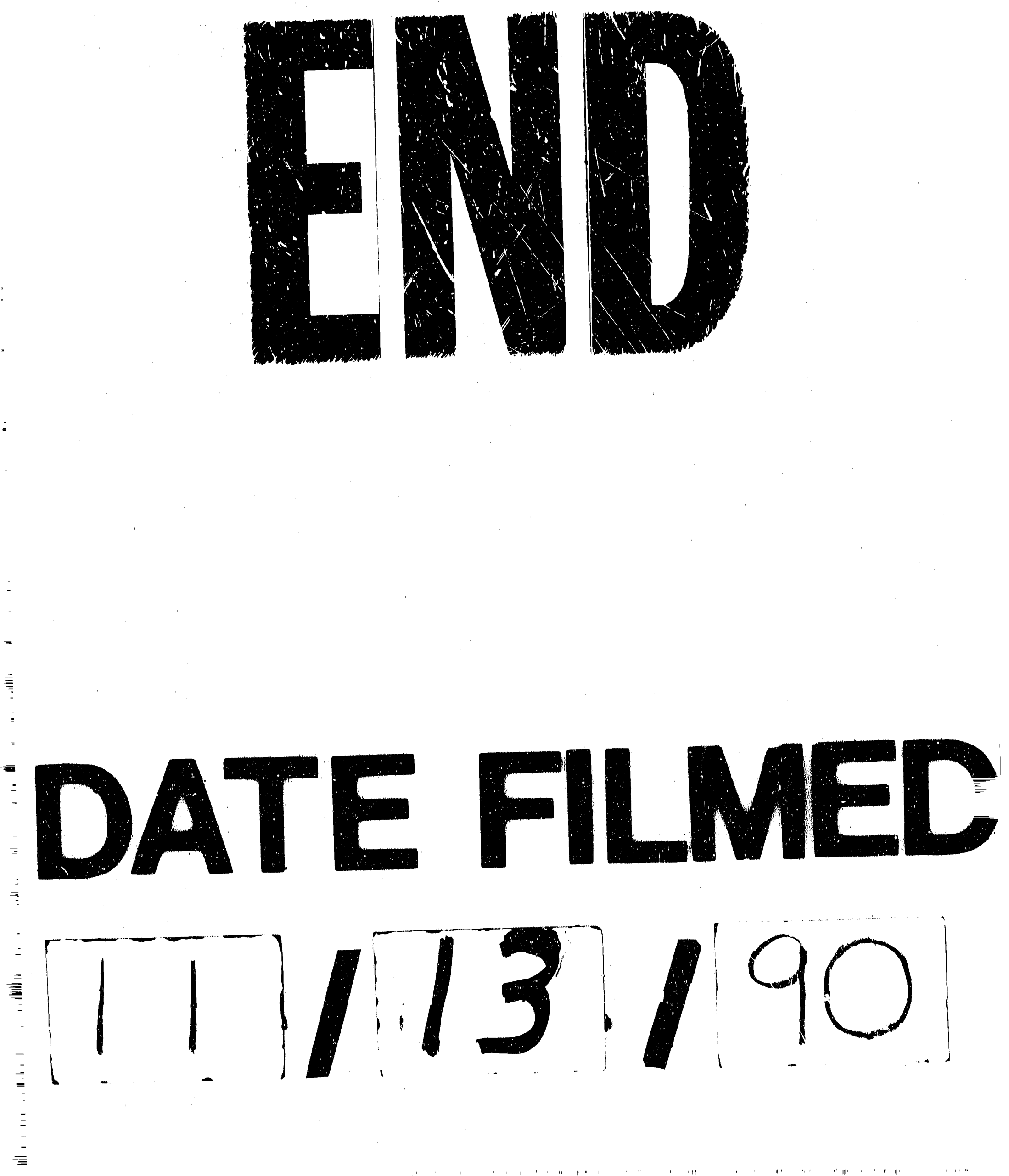


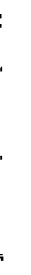

